\title{
Searching for Organizational Intelligence in the Evolution of Public-Sector Performance Management
}

\author{
Petri Virtanen, Jarmo Vakkuri
}

\begin{abstract}
The article explores the transformation process of evaluation, performance monitoring and accountability in the public sector. The process underlines that horizontal accountability referencing a wide democratic footprint is likely to become more explicit. To this end, this article develops the idea of transformation of public sector performance management from the viewpoint of organizational intelligence. Much of the current doctrine originates from rationalistic performance management and evaluation models and are therefore reluctant or unable to see the social mechanisms incorporated in the mechanisms of accountability. This article concludes that 'hard nose' rationalistic models of performance and evaluation are not anymore fit for purpose. To be measured by traditional performance metrics, the society is far too complex, constructed by various social networks and retrospective interlinkages, and constituted by public service systems. Thus, the need for intelligence in organizational knowledge management and decision-making processes ought to be addressed more systematically.
\end{abstract}

Key words:

performance management, organizational intelligence, social mechanisms

\section{Introduction}

Taking an argument by Bouckaert and Van Dooren (2009), Neely et al. (2006) and Bouckaert and Halligan (2008) as a starting point, all of whom conceive of the development of performance-management models and practices as an evolutionary process, this article develops the idea of the transformation of public-sector performance management from the viewpoint of organizational intelligence. This text explores the implications of this transformation for evaluation, performance moni- 
toring and accountability, underlining that horizontal accountability referencing a wide democratic footprint is likely to become more explicit (e.g. Schillemans 2011). We intend to pinpoint tentative answers to the critique which has evolved with regard to performance measurement and management during the last few decades. This critique has reflected both the use of performance information - or misuse or non-use, to be more precise - and the unintended institutional and behavioural effects of using performance information in public policy and public organizations (e.g. Heinrich 1999; Wholey and Hatry 1992; Patton 1997; van Helden et al. 2012).

Today, several questions regarding performance management remain more or less unanswered. First, there are systemic changes as societal challenges - that is globalization, technological development and innovations, changes in social values and perceptions, and climate change and ecological constraints. Overall, systemic changes represent a much broader theme than a mere economic issue because it is a result of changes in the quality and quantity of human beings, the stock of human knowledge, particularly as applied to human command over nature, and the institutional framework that defines that deliberative incentive structure of a society (North 2005). Public organizations ought to be resilient to these changes, and performance metrics ought to provide information on how this process proceeds (e.g. information about customer satisfaction, how public service delivery enhances service-user empowerment, what the role of public services systems is in the sphere of human life). Secondly, multi-level governance - global, national, regional and local governance mechanisms - constitute a form of vertical bureaucracy, coordination and division of labour, but in terms of planning and performance management the decision-making process is far from completely rational or clear (e.g. Vakkuri 2010). Multi-level governance structures also pave the way for complexity and interconnected policies - and performance management and evaluation models do not easily take this interconnectedness into account. Thirdly, methodological problems arise because of the complexity and interconnectedness of public policies and due to evolving intersections between the public and private sectors. Our article addresses these methodological problems.

The current paradigm of performance measurement and evaluation is primarily based on the assumption that societies can be governed by a rationalistic mode of thinking, often neglecting social mechanisms incorporated in the measurement of accountability systems and procedures. Furthermore, current modes of performance evaluation rely excessively on the assumption of entity-based evaluation: the idea that it is possible to detect performances within clear-cut organizational boundaries and to distinguish "public" from "private" performance (Hodges 2012). In modern publicadministration practice, it would be equally important to understand performances within collaborative networks and in contexts where both public- and private-sector actors contribute to final outcomes for citizens. There is an urgent need to solve the problem of "multiple accountabilities disorder" in providing solid information on public-sector performance (Koppell 2005; Bort et al. 2012). 
Our paper is a conceptual article, exploring further research possibilities for using the framework for organizational intelligence to enhance the understanding of evaluation, performance management and accountabilities in the public sector. The paper is organized as follows.

First, we discuss traditional evaluation and performance-management models and approaches. They contain certain pitfalls when they are associated with complex policy and public-service environments with an emphasis on "wicked policy problems" (e.g. Head 2008; Weber and Khademian 2008; Ferlie et al. 2011). The more complex society is, the more profound are the problems of evaluation and performance measurement that we face - both methodologically and conceptually. Secondly, we discuss the role of the changing context of public-sector organizations using the concept of organizational intelligence. When the context for public organizations changes, the prerequisites for performance management are also on the move. We will argue that intelligence in public-sector organizations requires a new understanding of seeing them as distributed knowledge systems and sense-making communities. Moreover, a new understanding of resilience is needed to capture the necessity for valid performance metrics, data and information. The final part of the paper provides conclusions and makes explicit notions for future research directions in the field of performance management and measurement. To this end, we build upon Weiss (1998), who, as one of many other authors, thinks that evaluation and performance management are a way to increase the rationality of policymaking.

\section{The impasse of the engineering logic of performance}

The evaluation of the outcomes of public policy and public organizations is one of the key elements in a policy process (e.g. Weiss 1998; Vedung 1997; Dahler-Larsen 2006). At first glance, the task of evaluation and performance management is clear-cut. It is the process of determining the merit, worth and value of things, and performance information is the product of that decision-making process (Scriven 1991, 1). However, professional evaluation and performance monitoring should not "only" be equated with the accumulation and summarizing of the data relevant for decision-making. The process of transforming information, based on performance indicators, relates to foresight, leadership and interpretation of knowledge. Before using performance "numbers", you have to understand the logic of what performance information consists of and how it is deployable.

Take the example of traditional logic models in evaluation research. It is tempting to use logic models when sketching, planning and implementing policies, programmes or projects. Who would resist the idea of captivating the crucial links between programme inputs, operations, outputs, results and impacts? From experience, we know that politicians and public-sector managers are in favour of finding 
logical links between public activities and their presumed effects. We think, however, that the world today is too complex for logic models. Policy and programme evaluation calls for different levels of intellectual synthesis. Fischer (1995), for instance, makes a distinction between programme verification, situational validation (coming very close to the idea of realistic evaluation, coined by Pawson and Tilley 1997), societal-level vindication and social choice.

In this text, however, we read Fischer (ibid.) mainly from the point of view of social mechanisms. The idea is not to look straightforward at performance "numbers", but to search for the social mechanisms behind performance management and evaluation systems. This view helps researchers and public managers pinpoint methodological flaws, which in performance monitoring and evaluation relate to the lack of understanding of social mechanisms that produce outcomes and to understanding the contextual factors that work under certain circumstances but might not produce the desired effect under others (see, e.g., Hedström and Swedberg 1998; Virtanen and Uusikylä 2004). Social mechanisms reveal additional problems in current performance-management practices. These problems concern the difficulties in finding reliable monitoring and evaluation indicators, aggregating data from outputs to outcomes and long-term impacts, proving the attribution and net effect of particular policy, programme and project interventions and finally utilizing evaluation findings in reformulating policies from the perspective of learning/unlearning organization. These are limitations in current performance systems and metrics.

Figure 1 illustrates the problem of the rationalistic mode of thinking, which we call engineering logic of performance. The main problem of this type of performance logic concerns the fact that this does not take into account the human aspect of planning and implementing public policies and delivering public services (March 1978). Figure 1 highlights the fact that a public policies or programmes are fields of action where societal actors base the courses of their actions on interpretations of the expected logic of a policy or a programme (cf. Vakkuri 2013). Actions in an organizational, policy-programme context are always socially constructed rather than objectively derived from abstract policy/programme logic.

Consequently, all policies interfere with an intervention field of social actors whose reactions actually produce the final "version" of the policy - and thus create the framework for performance reporting and the evaluation of the actual outcomes and effects of the policy. To summarize, in Figure 1 - and grounding our idea on Kaufmann (1987) in particular - the elaborated model (i.e. the mechanism-based explanation) begins with the idea that policies are always socially constructed. In practice, this means that certain agents develop and elaborate policies, which thereafter are delivered by other actors who might - and most often do - have their own interpretations of policy logic and its situational validation. The process described in Figure 1 indicates that the role of performance systems begins at the ex-ante stage of policy delivery. This notion is important in ensuring the validity and reliability of performance metrics. 


\section{Figure 1}

Two logics in understanding performance: the engineering model and the elaborated model (Virtanen and Uusikylä 2004; cf. March 1978)

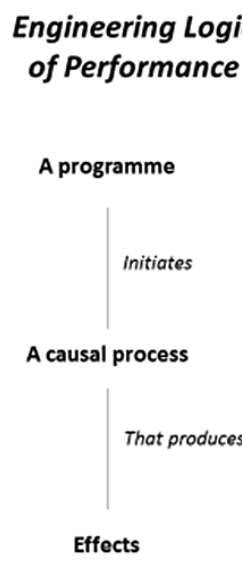

\section{Elaborated Model of Performance}

Actors
\[ \begin{array}{l}\text { Developed intentionally on the } \\ \text { basis of defined situations }\end{array} \]
A programme
Which is implemented
By other actors
Addresseesined with their intentions
and definitions of the situation
| $\begin{aligned} & \text { Whose reactions produce effects } \\ & \text { based on their intentions and } \\ & \text { definitions of the situation }\end{aligned}$
Effects

There is an obvious need for systemic performance management and evaluation models, based on social mechanisms incorporated in policy/programme/organizational planning by public-sector institutions. This would tackle various methodological flaws in policy, programme and project delivery as well as understanding the results and effects of public-sector organizations. The elaborated model described in Figure 1 opens up a new research agenda: how ambiguous strategy objectives really are, how different interpretations of effects exists with regard to public interventions (those being policies, organizations' activities or service-delivery outputs), how different views of performance are weighted and what causal relation exists between the cause and the effect. It is important to develop further insights into complex dynamic systems, uncertainty and nonlinearity, particularly in respect of their emergence into the domain of public policies, programmes, services and organizations.

\section{Enter Organizational Intelligence}

Next we discuss the role of organizational intelligence and ask: what is it and how can it alleviate the effects of misuse and non-use of performance information? Overall, the context of public-sector organizations has changed dramatically over the last few decades. The operating environment of public actions has become more complex, and public services have transformed into multifaceted and multidimensional service systems - or public services have been embedded into service ecosys- 
tems, constituted by public, private and non-governmental service providers. This has caused multiple methodological difficulties in measuring public organizations' performance and providing information accountability-wise. Today, when public organizations operate in network-based open systems, the role of information and organizational intelligence becomes a valuable commodity.

By definition, the intelligence of public-sector organizations is a distributed knowledge system or sense-making community, to put the idea forward by means of the terminology by Tsoukas (2005) and Choo (1998). This theoretical view holds that the knowledge resources a public-sector organization deploys are neither given nor discovered but created in the process of making sense of the knowledge. This comes very close to what Nonaka and Takeuchi (1995) have described as a process during which tacit knowledge is converted into explicit knowledge within the structures of a given organization. As knowledge becomes an asset in terms of organizational competitiveness, mechanisms of learning, unlearning and competencebuilding become incalculably valuable features.

Organizational intelligence, at first glance, would seem to be more related to the "engineering logic", as it is traditionally and primarily understood as the organization's ability to produce, process, store, retrieve, utilize and share knowledge relevant and instrumental to its purpose. Our argument is actually somewhat opposite to this presumption. If we accept the view that social mechanisms prevail (as described in Figure 1) in all phases of the performance-management processes, then the question of organizational intelligence arises, and knowledge-based leadership enters into the picture. Virtanen and Stenvall (2014), for instance, have argued that the intelligence of a public organization refers to two dimensions - to knowledge-based decision-making (including the constructionist way to build performance systems, management and metrics) and customer-centred thinking emphasizing the role of service-dominant logic in organizing public-service delivery. This view holds that an intelligent public organization - and public policy-making as well - develops consolidated knowledge-management systems which take the whole planning process into account - from strategy to implementation and from implementation to the evaluation of effects of public interventions.

We would like to underline that public-service delivery has matured during the last 10-15 years or so - and now there is an urgent need to look for new directions for performance management and evaluation. Namely, the new planning ideology has been built upon the New Public Governance principles; management has conveyed the idea that society, public policies and organizations cannot be governed without the capacity of managing networks and co-operation (e.g. Greve 2015). These networks exist at all levels of governance - that is, at the local, regional, national and global levels. Consequently, the time-frame logic of planning has also changed radically. Planning cycles are now shorter, and this calls for a new kind of reflexivity, in terms of both the agility of the public organizations and their performance systems. 
Organizational intelligence is thus a process determining the most appropriate performance-monitoring systems, the most valid performance indicators and the most efficient use of performance information in decision-making. This calls for a new kind of competencies in public organizations to understand performancemanagement systems' logic in terms of how information metrics are linked with target-setting in the strategy process, how retrospective and prospective types of performance indicators are deployed in performance metrics and how to make sure that outcome indicators really measure the effects of a specific public organization.

Targeting performance indicators and enhancing decision-making leadership capacity, however, are only limited solutions to performance-management dilemmas within the framework of intelligent public organizations. Research evidence suggests that resilience is one key feature of intelligent public-policy-making, programme implementation and "business intelligence" of public organizations (e.g. Hamel and Välikangas 2003; McManus et al. 2008; Kaivo-oja et al. 2015), and this underlines the role of solid and trustworthy performance-management models and metrics to ensure resilience. Resilience often relates to emergency management issues, which it is not the case when we look at it from the intelligent-public-organization point of view. In organizational terms, it refers to the capacity of making decisions based on valid performance information. Furthermore, resilience refers to an organization's capacity to anticipate disruptions, adapt to disruptive events and create lasting service-user value in a turbulent environment. Finally, from the organizational perspective, it is apparent that resilience does not occur by accident or by chance. On the contrary, it is the effect of intelligent actions, decision-making and leadership as well as converting organizational processes towards the mode of organizational learning and adjustment (e.g. Hernes 2014).

\section{Conclusions and Future Research Possibilities}

It is clear that performance management and evaluation provide much of the raison dêtre for public policies and public administration. We have argued that the role of systemic changes in society and the role of intelligence in public organizations should be properly addressed in discussing performance management and evaluation. Much of the current doctrine originates from rationalistic performance management and evaluation models and is therefore reluctant or unable to see the social mechanisms incorporated in the mechanisms of accountability (March 1978). Moreover, it seems that the academic discourse on performance management within the framework of public administration, policy analysis and management studies, economics, accounting and finance - has perhaps been rich in content, but to date still largely relies mainly on a simple rationalistic engineering logic of performance (van Helden et al. 2012). 
Two conclusions can be drawn here. First, it seems that "hard-nosed" rationalistic models of performance and evaluation are no longer fit for purpose. To be measured by traditional performance metrics, the society is far too complex, constructed by various social networks and retrospective interlinkages and constituted by public-service systems. There is an urgent need for further scientific research on how performance management and evaluation models are designed and implemented, how the performance information is used in organizational decision-making processes and what kind of impacts performance information has on organizations, service users, citizens and stakeholders. In such research efforts, the performance logic should not only be that of engineering logic, but it could incorporate more fully the features of different elaborated models. Therefore, the role of the human or the social aspect in the service of programme-delivery planning is of special interest here. We would argue that social mechanisms are some of the cornerstones not only to understand the applicability of performance metrics but also to revisit the role of public managers and decision-makers in public-sector performance improvements. This research-setting calls for a new kind of methodological and conceptual tools in the area of performance management and evaluation research. To put forward a couple of promising theoretical and conceptual possibilities, we would like to mention Pierre Bourdieu's field theory (e.g. Bourdieu 2000), empirical network analysis (e.g. Moran 2005) or modern systems theory (e.g. Checkland 1980).

Second, as the context for public-sector organizations becomes more complex, the need for intelligence in organizational-knowledge management and decision-making processes ought to be addressed more systematically. Many important perspectives, such as the organizational-intelligence point of view that we have addressed in the paper are therefore under-utilized. We think that the notion of organizational intelligence emphasizing the role of consolidated performancemanagement systems with changing environments can offer a theoretical and conceptual framework - to develop performance measurement in the setting, where wicked policy problems exist and where they are tackled by multi-institutional service systems. It is noteworthy to think that technologies related to knowledgemanagement - such as the Internet of Things, the Internet of Intelligent Things, Big Data, robotics, nanotechnology - will be upgraded in the future. This process paves the way for improved knowledge processes with public organizations. The issue at stake here is not in fact how to manage and control the technological possibilities, but rather to understand their interlinkages to performance monitoring, evaluation and smart leadership. Taking seriously disruptive and advanced technologies may lead towards the revolution of digitalization, which has a profound effect on management processes, service delivery and performance measurement in public organizations. 


\section{References}

Bort, E., R. McAlpine and G. Morgan. 2012. The Silent Crisis: Failure and Revival in Local Democracy in Scotland. Glasgow: The Jimmy Reid Foundation.

Bouckaert, G. and J. Halligan. 2008. Managing Performance: International Comparisons. London: Routledge.

Bouckaert, G. and W. Van Dooren. 2009. "Performance Measurement and Management in Public Sector Organizations.” In T. Bovaird and E. Löffler (eds). Public Management and Governance. London: Routledge. 151-164.

Bourdieu, P. 2000. Pascalian Meditations. Cambridge: Polity Press.

Checkland, P. 1980. “The Systems Movement and the 'Failure' of Management Science." Cybernetics and Systems 11(4), 317-324.

Choo, C. W. 1998. The Knowing Organization: How Organizations Use Information to Construct Meaning, Create Knowledge, and Make Decisions. Oxford: Oxford University Press.

Dahler-Larsen, P. 2006. "Evaluation after Disenchantment? Five Issues Shaping the Role of Evaluation in Society." In I. F. Shaw et al. (eds). The SAGE Handbook of Evaluation. Thousand Oaks: Sage Publications, 141-160.

Ferlie, E., L. Fitzgerald, G. McGivern, S. Dopson and C. Bennett. 2011. "Public Policy Networks and 'Wicked Problems': A Nascent Solution?” Public Administration 89(2), 307-324.

Fischer, F. 1995. Evaluating Public Policy. New York: Nelson-Hall Publishers.

Greve, C. 2015. “Ideas in Public Management Reform for the 2010s: Digitalization, Value Creation and Involvement." Public Organization Review 15(1), 49-65.

Hamel, G. and L. Välikangas. 2003. “The Quest for Resilience.” Harvard Business Review 81(9), 52-63.

Head, B. W. 2008. “Wicked Policy Problems." Public Policy 3(2), 101-118.

Hedström, P. and R. Swedberg (eds). 1998. Social Mechanisms: An Analytical Approach to Social Theory. Cambridge: Cambridge University Press.

Heinrich, C. J. 1999. "Do Government Bureaucrats Make Effective Use of Performance Management Information?" Journal of Public Administration Research and Theory 9(3), 363-394.

Hernes, T. 2014. A Process Theory of Organization. Oxford: Oxford University Press.

Hodges, R. 2012. "Joined-Up Government and the Challenges to Accounting and Accountability Researchers." Financial Accountability \& Management 28(1), $26-51$. 
Kaivo-oja, J., P. Virtanen, H. Jalonen and J. Stenvall. 2015. The Effects of the Internet of Things and Big Data to Organizations and their Knowledge Management Practices. KMO proceedings from the 2015 KMO Conference. Maribor: Springer.

Kaufmann, X.-F. 1987. "Prevention and Intervention in the Analytical Perspective of Guidance." In K. Hurrelmann et al. (eds). Social Intervention: Chances and Constraints. New York: Walter de Gruyter, 3-20.

Koppell, J. G. S. 2005. "Pathologies of Accountability: ICANN and the Challenge of 'Multiple Accountabilities Disorder." Public Administration Review 65(1), 94-108.

McManus, S., E. Seville, J. Vargo and D. Brunsdon. 2008. "Facilitated Process for Improving Organizational Resilience." Natural Hazards Review 9(2), 81-90.

March, J. G. 1978. "Bounded Rationality, Ambiguity and the Engineering of Choice." Bell Journal of Economics 9(2), 587-608.

Moran, P. 2005. "Structural vs. Relational Embeddedness: Social Capital and Managerial Performance." Strategic Management Journal 26(12), 1129-1151.

Neely, A., M. Kennerly and A. Walters. 2006. Performance Measurement and Management: Public and Private. Cranfield: Cranfield School of Management.

Nonaka, I. and H. Takeuchi. 1995. The Knowledge-Creating Company: How Japanese Companies Create the Dynamics of Innovation. Oxford: Oxford University Press.

North, D.C. 2005. Understanding the Process of Economic Change. Princeton, NJ: Princeton University Press.

Patton, M. Q. 1997. Utilization-Focused Evaluation: The New Century Text. Thousand Oaks: Sage Publications.

Pawson, R. and N. Tilley. 1997. Realistic Evaluation. London: Sage Publications.

Schillemans, T. 2011 "Does Horizontal Accountability Work? Evaluating Potential Remedies for the Accountability Deficit of Agencies." Administration \& Society 43(3), 387-416.

Scriven, M. 1991. Evaluation Thesaurus. Thousand Oaks: Sage Publications.

Tsoukas, H. 2005. Complex Knowledge: Studies in Organizational Epistemology. Oxford: Oxford University Press.

Vakkuri, J. 2013. "Interpretive Schemes in Public Sector Performance: Measurements Creating Managerial Problems in Local Government." International Journal of Public Sector Performance Management 2(2), 156-174.

Vakkuri, J. 2010. "Struggling with Ambiguity: Public Managers as Users of NPMOriented Management Instruments." Public Administration 88(4), 999-1024. 
Van Helden, G. J., Å. Johnsen and J. Vakkuri. 2012. “Evaluating Public Sector Performance Management: The Life Cycle Approach.” Evaluation 18(2), 159-175.

Vedung, E. 1997. Public Policy and Program Evaluation. New Brunswick: Transaction Publishers.

Virtanen, P. and J. Stenvall. 2014. Älykäs julkinen organisaatio [An intelligent public organization]. Helsinki: Tietosanoma.

Virtanen, P. and P. Uusikylä. 2004. "Exploring the Missing Links between Cause and Effect: A Conceptual Framework for Understanding Micro-Macro Conversions in Programme Evaluation." Evaluation 10(1), 77-91.

Weber, E. P. and A. N. Khademian. 2008. "Wicked Problems, Knowledge Challenges, and Collaborative Capacity Builders in Network Settings." Public Administration Review 68(2), 334-349.

Weiss, C. 1998. Evaluation. Upper Saddle River, New Jersey: Prentice-Hall.

Wholey, J. S. and H. P. Hatry. 1992. “The Case for Performance Monitoring." Public Administration Review 52(6), 604-610. 